\title{
Dipole Moment of Urea Molecule on Gas Phase and Solvent
}

\author{
Antonio L. de Almeida ${ }^{1(\mathrm{PQ})}$, Débora M. Matos(IC) ${ }^{1}$ and João B. L. Martins ${ }^{2(\mathrm{PQ})}$ \\ ${ }^{1}$ Universidade do Estado da Bahia, Departamento de Ciências Exatas e da Terra, Rua Silveira Martins, \\ 2555, Cabula, Salvador-BA, CEP:41.150-00. Brazil. \\ ${ }^{2}$ Universidade de Brasília, Instituto de Química, CP 04478, Campus Universitário, Brasília, DF, 70919 - \\ 970, Brazil.

\section{E-mail: lopes@unb.br}

Key Word: Dipole Moment, Gas Phase, Solvent, Density functional theory.

\section{Introduction}

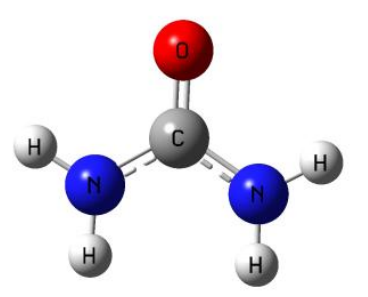

The importance of UREA $\left(\mathrm{CH}_{4} \mathrm{~N}_{2} \mathrm{O}\right)$ as fertilizer in the agricultural industry has grown enormously in recent years and according to all forecasts. Thus, a detailed understanding of its reaction mode with the soil is of fundamental importance. An investigation of the electrical characteristics of a molecule gives important information on the distribution of charges in the molecule and provides the possibility of determining many properties of the molecule which depend on its electronic distribution. In this work, based on the calculations of quantum chemistry, we verify the effect of the solvents at the moment of electric dipole of the urea molecule. Solvent effects were analyzed with the use for calculations of the Polarizable Continuum Model (PCM) as the default in self-consistent reaction field (SCRF) method. The PCM method treats the continuum as a polarizable dielectric $\mathcal{E}$. For Gas Phase $\mathcal{E}=1$, Chloroform solvent $\mathcal{E}=4.711$, and Water $\mathcal{E}=78.3553$. For all calculations we used Density Functional Theory (DFT) with WP04/aug-ccpVTZ theory lavel in Gaussian09 Package Program.

\begin{tabular}{cc}
\hline \multicolumn{2}{c}{ Gas Phase } \\
\hline Dipole moment $\mu$ (Debye) \\
\hline Parameter $\quad$ Value \\
\hline
\end{tabular}

\begin{tabular}{cc}
\hline \multicolumn{2}{c}{ Chloroform Solvent } \\
\hline \multicolumn{2}{c}{ Dipole moment $\mu$ (Debye) } \\
\hline Parameter & Value \\
\hline
\end{tabular}

\begin{tabular}{cc}
$\frac{\text { Water Solvent }}{\text { Dipole moment } \mu \text { (Debye) }}$ \\
\hline Parameter $\quad$ Value \\
\hline
\end{tabular}

\section{Conclusions:}

Based on the table values for the chemical shifts, It is necessary to see the inclusion of solvents for a better understanding of the molecular electronic structure of the urea molecule.

\section{Referênciais:}

Wolfram Koch, Max C. A Chemist's Guide to Density Functional Theory, Second Edition

\section{Acknowledgments:}

The authors thank to CNPq, UNEB, UnB, FINATEC, CAPES and FAPDF. 